\title{
Performances analysis of interior permanent magnet motors having different rotor iron pole shapes
}

\author{
Ahlam Luaibi Shuraiji, Buraq Abdulhadi Awad \\ Electromechanical Engineering Department, University of Technology, Baghdad, Iraq
}

\begin{tabular}{l} 
Article Info \\
\hline Article history: \\
Received Sep 28, 2020 \\
Revised Aug 24, 2021 \\
Accepted Sep 2, 2021 \\
\hline
\end{tabular}

Keywords:

Cogging torque

Elecromagnetic torque

Interior permanent magnet

machine

Torque-speed curve

\begin{abstract}
Interior permanent magnet motors (IPMMs) have been increasing in popularity, since the emergence of permanent magnet material with high energy products, i.e., rare earth permanent magnet material. This paper analyses the performances of IPMMs having different rotor iron pole shapes including eccentric, sinusoidal and sinusoidal with $3^{\text {th }}$ order harmonic injected rotor pole arc shapes IPMMs. Cogging torque, static torque, torque ripple, torque-speed and power-speed curves of the mentioned motors have been compared. It must be noted that the mentioned motors have been designed with the same stator, PM shape and the same dimensions, in order to highlight the effect of the rotor pole arc shape on the performance of the such motors. Two-dimensional (2D) finite element analysis (FEA) has been utilized to design and analyze the mentioned machines. It has been found that rotor iron pole shape of the IPM has notably influence on the machine performance, practically on output electromagnetic torque and its ripple. The highest value of average electromagnetic torque as well as torque capability in the constant torque reign is delivered by 3 th order harmonic injected rotor pole arc shapes machine, while the lowest torque ripple is obtained by the sinusoidal rotor pole arc machine.
\end{abstract}

This is an open access article under the CC BY-SA license.

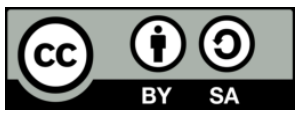

\section{Corresponding Author:}

Ahlam Luaibi Shuraiji

Departement of Electromechnical Engineering

Uinversity of Technology

Baghdad, Iraq

Email: ahlamly2009@yahoo.com

\section{INTRODUCTION}

Interior permanent magnet motors (IPMMs) have been considered as prospective candidates for many applications, because of the evident advantages of such machines [1]-[6]. As IPMMs are manufacturing with buried PM in the rotor iron, the reliability of the machines would be boosted by enhancing the mechanical strength and increasing the demagnetization withdraw capability. Besides, such structure results in higher electromagnetic torque compared to other PM machines configurations, due to the present of the reluctance torque [7]-[13]. Enhancing average torque capability of the IPMMs have been of interesting in many literatures. Some researches focus on the position as well as the configuration of the magnet, as such parameters have a critical role on the performances of the IPMMs [14]. It is worth mentioning that IPMMS have been introduced with four different PM configurations, i.e., I-type, spoke-type, V-type and U-type. Literatures reveled that each configuration has advantages and disadvantages compared to the other [15], [16]. While the V-type machine delivered the highest torque capability, rotor iron saturation is the main problem in such structure. On the other hand, the spoke-type machine is characterized by the advantage of flux focusing, whereas flux leakage is the main demerit. Moreover, the I-type machine shows the lowest torque capability, however it has the best magnet 
utilization among the other configurations. Furtnermore, Yoon and Baek [17] have introduced IPM with flared PM shape. It was deliverd higher effecinecy and lower noise have been obtained by the introduced configuration compared to the conventional spoke configuration. Another area of improving the IPMMs torque capability is considering the winding configuration of such machines. Tangudu and Jahns [18] compared IPM machines with fractional slot (FS) concentrated windings and integral slot (IS) distributed windings. It was stated that both configurations deliver comparable torque, however the fractional-slot concentrated windings offer the merits of less copper usage and low copper losses, while the integral-slot distributed windings possess the advantage of higher reluctance torque, lower magnet usage as well as less rotor losses at high speed. Moreover, Abdel-Khalik et al. [19] introduced an IPMM with dual three-phase four-layer fractional-slot concentrated windings. Although the machine offers the same torque capability when it is compared to the conventional machine, it possesses lower iron and magnet losses, which help to improve the efficiency of the machine. Furthermore, rotor iron pole shape of the IPMMs is another aspect to be considered to improve the torque capability of such machines.

Recently, Wang et al. [20] discussed rotor iron pole shape technique to enhance the torque of the IPMM. Three different rotor pole shapes including conventional, sinusoidal and sinusoidal $+3^{\text {th }}$ order harmonic injected were designed and compared. It was revealed that the sinusoidal $+3^{\text {th }}$ order harmonic injected topology showed the highest average torque among the investigated topologies. It must be mentioned that torque ripple has not been of interested in the mentioned study, i.e., the authors focused on the torque capability enhancement only. Generally, torque fluctuating, which is mainly contributed by cogging-torque could be seen as an essential demerit of the PM machines [21]. It has been shown that reduction of such inherit feature of the PM machines would result in reducing of their average torques. Hence, unlike the above-mentioned literatures, the current study focuses on evolution the performances of IPMMs having different rotor iron pole shapes considering the cogging torque and consequently the torque ripple. The performances including: cogging torque, average electromagnetic torque, torque ripple, torque-speed and power-speed curves. In order to carry out a logical comparison, three IPMMs, i.e., eccentric, sinusoidal and sinusoidal $+3^{\text {th }}$ order harmonic injected rotor pole iron shapes are designed and optimized for maximum average torque and minimum torque ripple. It should be noted that the design, optimization and the performance analysis of all the understudying motors have been carried out using 2-dimentions finite element analysis (2D-FEA) Maxwell Ansoft software. The rests of the paper are organized as sjown in: Section 2 introduces the investigated topologies, while machines optimizations are discussed in Section 3. Whereas the machines performances are analyzed and compared in section 4, and finally, the conclusion is presented in section 5 .

\section{MACHINES CONFIGURATIONS}

Figure 1 depicts stator and rotor configurations of the understudying machines, and Table 1 illustrates the dimensions of the machines. Apparently, the machines have the same stator, PM configuration and winding layout. The only different is the rotor iron pole structure. Machine 1 has eccentric rotor iron pole, machine 2 has sinusoidal rotor iron pole, while machine 3 represents sinusoidal with $3^{\text {th }}$ order harmonic injected rotor iron pole. The machines are designed with fractional-slot concentrated winding, which offers the advantage of less copper usage leading to efficiency enhancement [22]. The stator has 12 slots, while the rotor has 4-pole pairs. To obtain sinusoidal flux density in the air-gap, the length of the air-gap is determined by (1) [23].

$$
l_{g}=\frac{l_{g \min }}{\cos (p \theta)}
$$

where $l_{g}$ indicts air-gap length, $l_{\text {gmin }}$ is the minimum air-gap length, $p$ is an integer (the pole pair number), and $\theta$ represents the pole arc angle.

On the other hand, the general equation to determine the air-gap length of the sinusoidal $+3^{\text {th }}$ harmonic shape rotor is expressed by [24].

$$
l_{g}=\frac{k(a) l_{g \min }}{\cos (p \theta)+a \cos (3 p \theta)}
$$

where $k(a)$ is a variable, which varies with the amplitude of the injected $3^{\text {th }}$ harmonic, while $a$ represents the amplitude of the injected $3^{\text {th }}$ harmonic. Unlike the sinusoidal rotor shape machine in which minimum length of the air-gap is located on the d-axis, the location of the minimum air gap length of the sinusoidal $+3^{\text {th }}$ harmonic rotor shape machine varies with the amplitude of the injected $3^{\text {th }}$ harmonic. Since both $\mathrm{d}-$ and $\mathrm{q}-$ axis lengths of the air gap are varied with the amplitude of the injected $3^{\text {th }}$ harmonic, optimal amplitude of 
such feature exists for maximum air gap flux density, and consequently the highest torque density. According to [20] it has been found that the optimal value of the $3^{\text {th }}$ harmonic was $1 / 6$. Thereby, the amplitude of the injected $3^{\text {th }}$ harmonic for machine 3 is $1 / 6$.

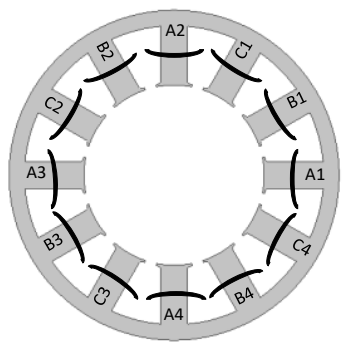

(a)

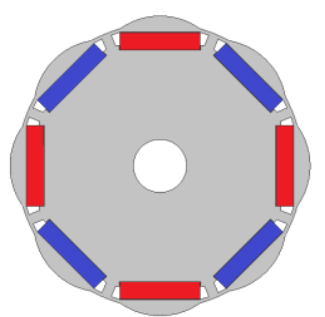

(b)

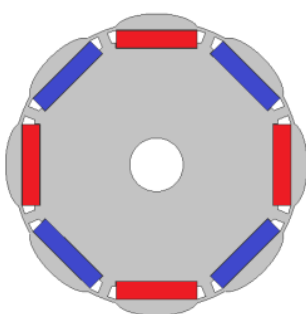

(c)

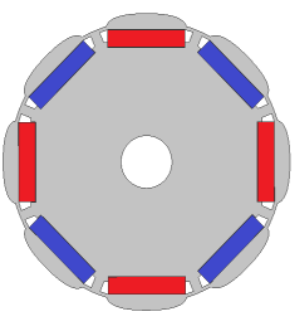

(d)

Figure 1. Machines structures; (a) stator structure and winding layouts, (b) eccentric (machine 1),

(c) sinusoidal (machine 2 ), (d) sinusoidal with $3^{\text {th }}$ order harmonic injected (machine 3 )

Table 1. Specifications of the machines

\begin{tabular}{ccc}
\hline Items & Values & Unites \\
\hline Outer stator diameter & 85 & $\mathrm{~mm}$ \\
Inner stator diameter & 26 & $\mathrm{~mm}$ \\
Minimum air gap length & 0.6 & $\mathrm{~mm}$ \\
Shaft diameter & 8 & $\mathrm{~mm}$ \\
Z-direction length & 38 & $\mathrm{~mm}$ \\
Slot open & 3 & $\mathrm{~mm}$ \\
Number of trues per coil & 13 & \\
Magnet $\mathrm{Br}$ & 1.38 & Tesla \\
\hline
\end{tabular}

\section{ROTOR OPTIMIZATION}

With the aid of the Maxwell Ansoft software and based on genetic algorithm (GA), global optimization of the rotor iron rotor shape has been carried out aiming minimum torque ripple and maximum torque for the understudying machines. Unchanging parameters through the optimization process are iron bridge dimensions, PM dimensions, minimum air gap length. Otherwise, the changed parameters during the optimization are listed in Table 2, while Table 3 shows the optimal values of such parameters.

Table 2. Restriction, optimal values of globally optimized parameters

\begin{tabular}{cccc}
\hline Items & \multicolumn{3}{c}{ Restrictions } \\
& Machine 1 & Machine 2 & Machine 3 \\
\hline Current angle (Deg.) & $5-25$ & $5-25$ & $5-25$ \\
Pole arc angle (Deg.) & - & $12-18$ & $12-18$ \\
Eccentric distance (mm) & $11-18$ & - & - \\
\hline
\end{tabular}

Table 3. Optimal values of globally optimized parameters

\begin{tabular}{cccc}
\hline Items & Machine 1 & Machine 2 & Machine 3 \\
\hline Current angle (Deg.) & 13.2 & 13.6 & 14.8 \\
Pole arc angle (Deg.) & - & 17.2 & 16.5 \\
Eccentric distance (mm) & 11.9 & - & - \\
\hline
\end{tabular}




\section{PERFORMANCE ANALYSIS}

\subsection{Open circuit and on-load}

The performances of the globally optimized machines will be examined in this section. Magnetic flux lines distributions are shown in Figure 2. while, predicated air gap flux density for one mechanical cycle at no load for all the machines are compared in Figure 3. Cleary, the peak of this feature is shaping according to the rotor iron pole. Machine 3 possesses the highest air gap flux density among the other machines. Furthermore, cogging torque waveforms for one electrical cycle are depicted in Figure 4. Obviously, machine 3 shows the highest cogging torque followed by machine1, while machine 2 delivers the lowest cogging torque. Cogging torque may be considered as the main inheriting problem of the PM machine. Such demerit feature caused by the interaction between the stator teeth and rotor permanent magnet. It is leading to torque ripple, noise and vibration. Additionally, the electromagnetic torques of the understudying machines for one electrical cycle and the torque ripple are displayed in Figures 5 and 6, respectively. Notably, the highest torque capability is delivered by machine 3 followed by machine 2, while machine 1 has the lowest torque. Additionally, machine 3 shows the lowest torque ripple among the other machines, while the highest value is for machine 3 .

\subsection{Torque-speed curve}

Generally, output electromagnetic torque of IPM machine can be described by (3),

$$
T=\frac{3}{2} N_{R}\left[\psi_{d} I_{q}-\psi_{q} I_{d}\right]=\frac{3}{2} N_{R}\left[\psi_{m} I_{q}+\left(L_{d}-L_{q}\right) I_{d} I_{q}\right]
$$

where $N_{R}, \psi_{m}, \psi_{d}, \psi_{q}, L_{d}, L_{q}, I_{d}$, and $I_{q}$ represent rotor pole pair number, PM flux-linkage, dq-axis fluxlinkage, inductances and current, respectively, the output torque consist of electromagnetic $\left(\psi_{m} I_{q}\right)$ and reluctance torque $\left(\left(L_{d}-L_{q}\right) I_{d} I_{q}\right)$ this results from the difference between d-axis and q-axis inductances. Torque-speed characteristics of the understudying machines are obtained by utilizing the method that was explained in [25] in which both d- and q-axis inductances are calculated for different values of $I_{d}$, and $I_{q}$ currents. Putting the predicted values of inductances and the PM flux in (3), the torque-speed curve will be obtained. The torque-speed performances of the mentioned machines are illustrated in Figure 7. Although machine 3 shows the highest torque capability in the constant torque section, it has the lowest weakening flux capability compared to other machines. This is because such machine possesses the highest airgap flux density and consequently the highest PM flux-linkage.

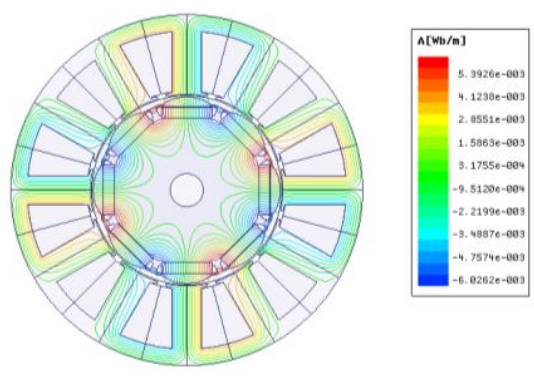

(a)

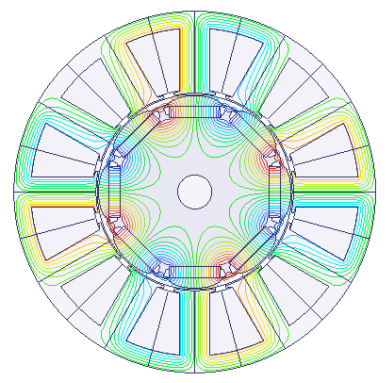

(b)
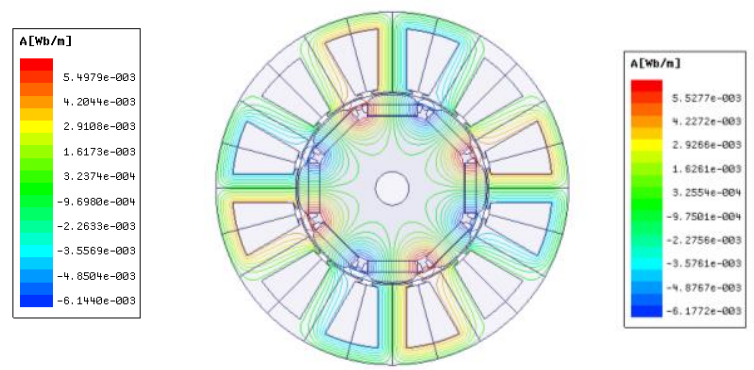

(c)

Figure 2. Field distribution at no load condition; (a) machine 1, (b) machine 2, (c) machine 3 


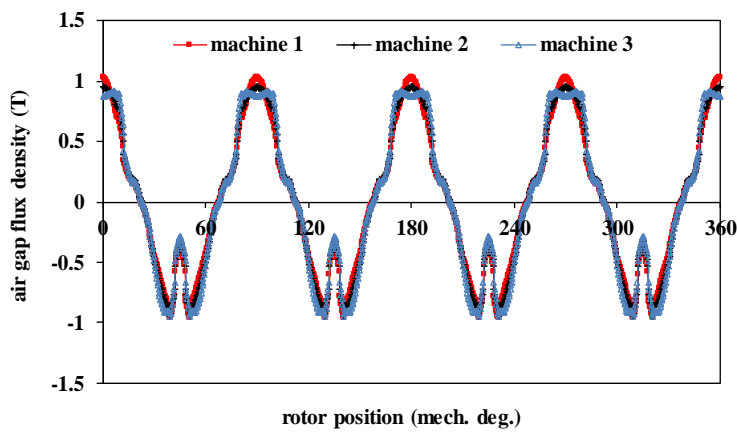

(a)

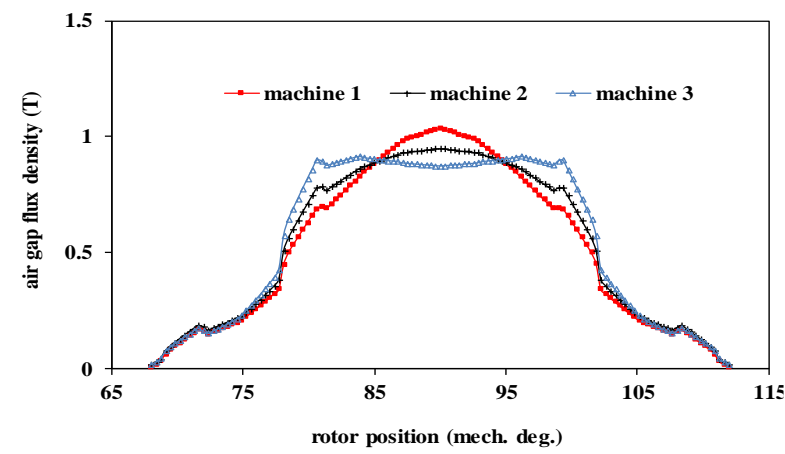

(b)

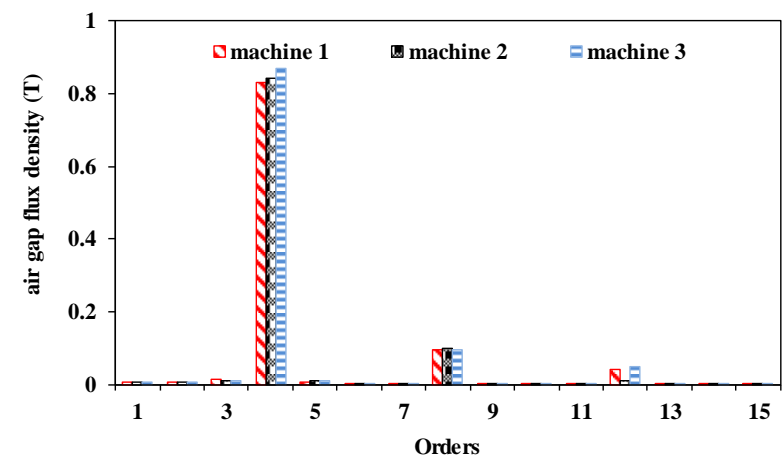

(c)

Figure 3. Air gap flux density comparison; (a) variation of the air gap flux density with rotor position, (b) zoom in on the air gap flux density peaks, (c) FFT

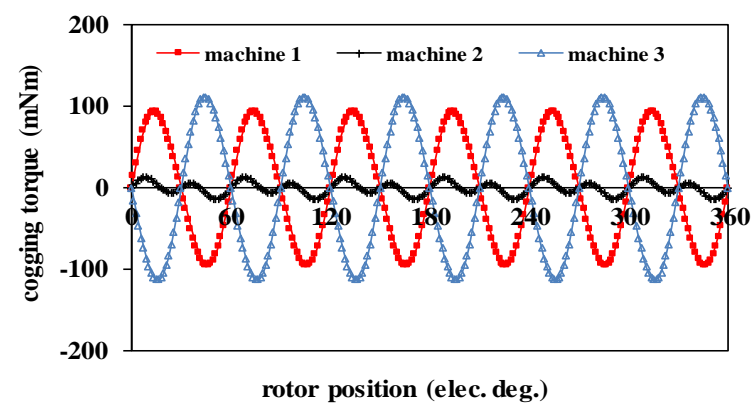

Figure 4. Cogging torque comparison

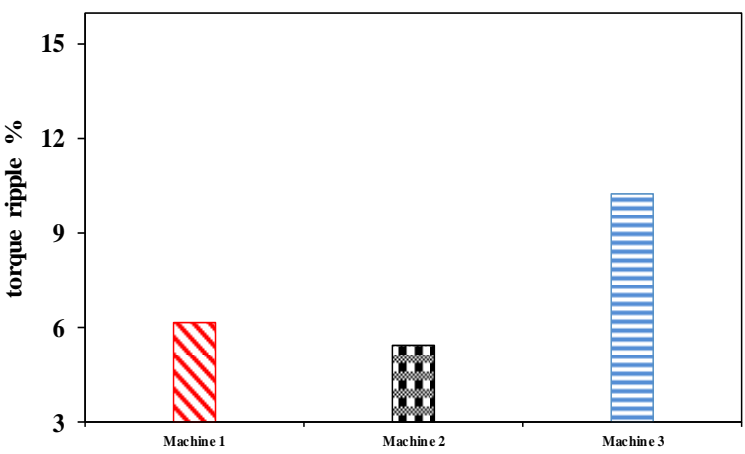

Figure 6. Torque ripple comparsion

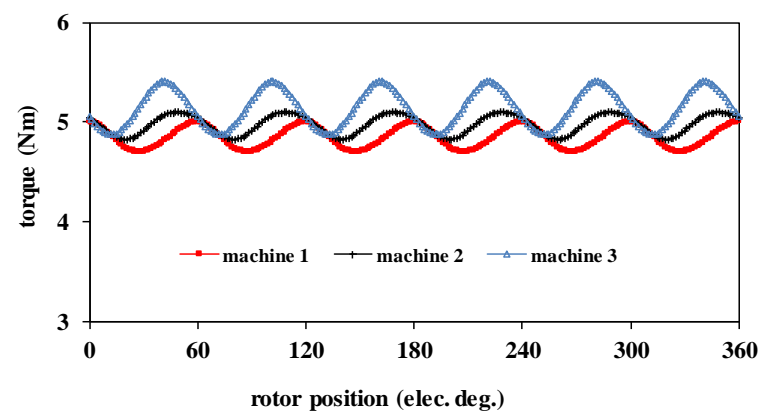

Figure 5. Electromagnetic torque comparison

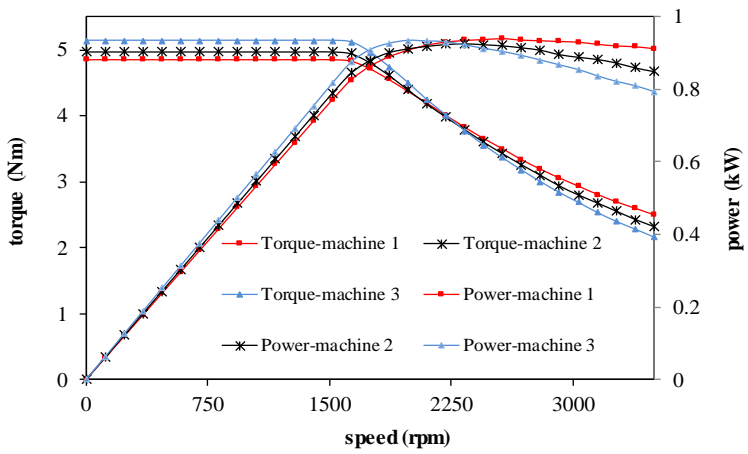

Figure 7. Torque-speed curve comparison 


\section{CONCLUSION}

The impact of rotor iron pole profile on the performance of the torque of IPM machine has been explored. In order to highlight the effect of such feature, three IPM machines having the same stator strucutres and the same specififcations with different rotor iron pole shape, i.e., eccentric rotor iron pole, sinusoidal rotor iron pole and sinusoidal with $3^{\text {th }}$ order harmonic injected rotor iron pole shapes have been designed. The rotor iron poles of the machines are globally optimized to obtain maximum average output electromagnetic touque and minimum torque ripple. 2D-FEA is used to design and analysie the understudying machines. Cogging torque, electromagnetic torque, torque ripple and torque, power-speed curves of the mentioned machines have been investigated and comapred. It is shown that the IPM machine, which has sinusoidal with thrid order harmonic injected rotor iron shape delivers the highest average torque and the highest torque at constant torque region. Incontast, it has the lowest flux weakening capability compared to other machines. Moreover, the sinusoidal rotor pole iron shape machine exhibts the lowest cogging torque and consequently the lowest torque ripple. While, the eccentric rotor iron pole shape machine has the highest power on power constant region.

\section{REFERENCES}

[1] P. B. Reddy, K. Huh, and A. M. EL-Refaie, "Generalized approach of stator shifting in interior permanent-magnet machines equipped with fractional-slot concentrated windings," in IEEE Transactions on Industrial Electronics, vol. 61, no. 9, pp. 5035-5046, Sept. 2014, doi: 10.1109/TIE.2013.2297515.

[2] H. Mirahki, and M. Moallem, "Design improvement of interior permanent magnet synchronous machine for integrated starter alternator application," 2013 International Electric Machines \& Drives Conference, 2013, pp. 382-385, doi: 10.1109/IEMDC.2013.6556279.

[3] S. Kim, S. Park, T. Park, J. Cho, W. Kim, and S. Lim, "Investigation and experimental verification of a novel spoke-type ferrite-magnet motor for electric-vehicle traction drive applications," in IEEE Transactions on Industrial Electronics, vol. 61, no. 10, pp. 5763-5770, Oct. 2014, doi: 10.1109/TIE.2014.2304697.

[4] S. Kim, J. Cho, S. Park, T. Park, and S. Lim, "Characteristics comparison of a conventional and modified spoketype ferrite magnet motor for traction drives of low-speed electric vehicles," 2012 IEEE Energy Conversion Congress and Exposition (ECCE), 2012, pp. 3048-3054, doi: 10.1109/ECCE.2012.6342358.

[5] T. Finken, M. Hombitzer, and K. Hameyer, "Study and comparison of several permanent-magnet excited rotor types regarding their applicability in electric vehicles," Emobility-Electrical Power Train, Nov. 2010.

[6] A. Chiba, Y. Takano, M. Takeno, T. Imakawa, N. Hoshi, M. Takemoto, and S. Ogasawara, "Torque density and efficiency improvements of a switched reluctance motor without rare-earth material for hybrid vehicles," IEEE Trans Indus. App., vol. 47, no. 3, pp. 1240-1246, May-June 2011, doi: 10.1109/ECCE.2010.5618025.

[7] Z. Azar, Z. Q. Zhu, and G. Ombach, "Investigation of torque-speed characteristics and cogging torque of fractional-slot IPM brushless AC machines having alternate slot openings," in IEEE Transactions on Industry Applications, vol. 48, no. 3, pp. 903-912, May-June 2012, doi: 10.1109/TIA.2012.2190962.

[8] A. R. Munoz, F. Liang, and M. W. Degner, "Evaluation of interior PM and surface PM synchronous machines with distributed and concentrated windings," 2008 34th Annual Conference of IEEE Industrial Electronics, 2008, pp. 1189-1193, doi: 10.1109/IECON.2008.4758123.

[9] K. I. Laskaris, and A. G. Kladas, "Internal permanent magnet motor design for electric vehicle drive," in IEEE Transactions on Industrial Electronics, vol. 57, no. 1, pp. 138-145, Jan. 2010, doi: 10.1109/TIE.2009.2033086.

[10] A. Fasolo, L. Alberti, and N. Bianchi, "Performance comparison between switching-flux and IPM machine with rare earth and ferrite PMs," 2012 XXth International Conference on Electrical Machines, 2012, pp. 731-737, doi: 10.1109/ICElMach.2012.6349955.

[11] J. Zheng, W. Zhao, C. H. T. Lee, J. Ji, and G. Xu, "Improvement torque performances of interior permanentmagnet machines," in CES Transactions on Electrical Machines and Systems, vol. 3, no. 1, pp. 12-18, March 2019, doi: 10.30941/CESTEMS.2019.00003.

[12] B. Lee, K. Kim, J. Jung, J. Hong, and Y. Kim, "Temperature estimation of IPMSM using thermal equivalent circuit," in IEEE Transactions on Magnetics, vol. 48, no. 11, pp. 2949-2952, Nov. 2012, doi: 10.1109/TMAG.2012.2196503.

[13] H. Kim, D. Kim, and J. Hong, "Structure of concentrated-flux-type interior permanent-magnet synchronous motors using ferrite permanent magnets," in IEEE Transactions on Magnetics, vol. 50, no. 11, pp. 1-4, Nov. 2014, Art no. 8206704, doi: 10.1109/TMAG.2014.2323818.

[14] D. Evans, Z. Azar, L. J. Wu, and Z. Q. Zhu, "Comparison of optimal design and performance of PM machines having non-overlapping windings and different rotor topologies," 5th IET International Conference on Power Electronics, Machines and Drives (PEMD 2010), 2010, pp. 1-7, doi: 10.1049/cp.2010.0201.

[15] X. Liu, H. Chen, J. Zhao, and A. Belahcen, "Research on the Performances and Parameters of Interior PMSM Used for Electric Vehicles," IEEE Transactions on Industrial Electronics, vol. 63, no. 6, pp. 3533-3545, June 2016, doi: 10.1109/TIE.2016.2524415.

[16] F. Charih, F. Dubas, C. Espanet, and D. Chamagne, "Performances comparison of PM machines with different rotor topologies and similar slot and pole numbers," International Symposium on Power Electronics Power Electronics, Electrical Drives, Automation and Motion, 2012, pp. 56-59, doi: 10.1109/SPEEDAM.2012.6264399.

[17] K. Y. Yoon, and S. W. Baek, "Performance improvement of concentrated-flux type IPM PMSM Motor with Flared-Shape Magnet Arrangement," Applied Sciences, vol. 10, no. 17, p. 6061, 2020, doi: 10.3390/app10176061. 
[18] J. K. Tangudu, and T. M. Jahns, "Comparison of interior PM machines with concentrated and distributed stator windings for traction applications," 2011 IEEE Vehicle Power and Propulsion Conference, 2011, pp. 1-8, doi: 10.1109/VPPC.2011.6043171.

[19] A. S. Abdel-Khalik, S. Ahmed, and A. M. Massoud, "Effect of multilayer windings with different stator winding connections on interior PM machines for EV applications," in IEEE Transactions on Magnetics, vol. 52, no. 2, pp. 1-7, Feb. 2016, Art no. 8100807, doi: 10.1109/TMAG.2015.2495301.

[20] K. Wang, Z. Q. Zhu, G. Ombach, and W. Chlebosz, "Average torque improvement of interior permanent-magnet machine using third harmonic in rotor shape," in IEEE Transactions on Industrial Electronics, vol. 61, no. 9, pp. 5047-5057, Sept. 2014, doi: 10.1109/TIE.2013.2286085.

[21] X. Ge, and Z. Q. Zhu, "Sensitivity of manufacturing tolerances on cogging torque in interior permanent magnet machines with different slot/pole number combinations," in IEEE Transactions on Industry Applications, vol. 53, no. 4, pp. 3557-3567, July-Aug. 2017, doi: 10.1109/TIA.2017.2693258.

[22] A. M. EL-Refaie, "Fractional-slot concentrated-windings synchronous permanent magnet machines: opportunities and challenges," in IEEE Transactions on Industrial Electronics, vol. 57, no. 1, pp. 107-121, Jan. 2010, doi: 10.1109/TIE.2009.2030211.

[23] S. A. Evans, "Salient pole shoe shapes of interior permanent magnet synchronous machines," The XIX International Conference on Electrical Machines - ICEM 2010, 2010, pp. 1-6, doi: 10.1109/ICELMACH.2010.5607694.

[24] K. Wang, Z. Q. Zhu, G. Ombach, and W. Chlebosz, "Optimal rotor shape with third harmonic for maximizing torque and minimizing torque ripple in IPM motors," 2012 XXth International Conference on Electrical Machines, 2012, pp. 397-403, doi: 10.1109/ICElMach.2012.6349898.

[25] Z. Q. Zhu, and X. Liu, "Individual and global optimization of switched flux permanent magnet motors," 2011 International Conference on Electrical Machines and Systems, 2011, pp. 1-6, doi: 10.1109/ICEMS.2011.6073806.

\section{BIOGRAPHIES OF AUTHORS}

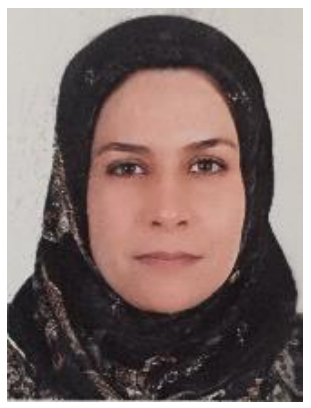

Ahlam Luaibi Shuraiji received the B.Eng. and M.Sc. degrees in Engineering Educational Technology/ Electrical Engineering, from University of Technology, Baghdad, Iraq, in 1998 and 2004, respectively, and the Ph.D. degree in electrical engineering from The University of Sheffield, Sheffield, U.K., in 2017. She is currently a lecturer at the University of Technology/ Electromechanical Engineering department. Her research interests include the design of permanent-magnet machines

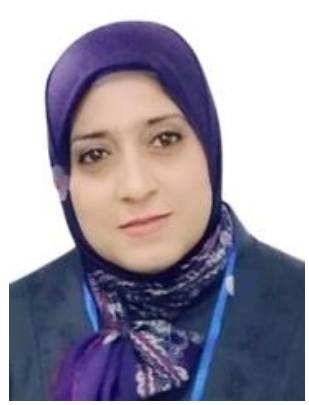

Buraq Abdulhadi Awad received the B.Eng. and M.Sc. degrees in Engineering Educational Technology/ Electrical Engineering, from University of Technology, Baghdad, Iraq, in 1998 and 2005, respectively. She is currently a lecturer at the University of Technology/ Electromechanical Engineering department. Her research interests include power electronic and control 